
Mr Dalibor Petrović,
poručnik, dipl. inž.
VP 3065 Sombor

\section{SOFTVER ZA PRORAČUN UZDUŽNE STATIČKE STABILNOSTI I UPRAVLJIVOSTI AVIONA ZA OSNOVNU OBUKU PILOTA}

UDC: $629.7 .017 .2: 623.746 .7: 004.4$

Rezime:

U ovom radu opisan je softver za proračun uzdužne statičke stabilnosti $i$ upravljivosti aviona za osnovnu obuku pilota. Softver je urađen sa namerom da konstruktorima omogući brzo i lako dobijanje potrebnih rezultata vezanih za stabilnost $i$ upravljivost kod preliminarnih proračuna vezanih za ovu vrstu aviona. Program je urađen na osnovu analize velikog broja aviona iz ove klase, a njegova tačnost je testirana na avionu „Lasta“. Rezultati koji su dobijeni ovim softverom bili su više od zadovoljavajućih, s obzirom na to da se radi o programu koji bi se koristio za preliminarni proračun.

Ključne reči: uzdužna statička stabilnost, upravljivost, težište, rezerva stabilnosti, neutralna tačka.

\title{
SOFTWARE FOR CALCULATION OF AN AXIAL STATIC STABILITY AND MANAGEMENT OF AIRPLANES FOR BASIC PILOT TRAINING
}

Summary:

This document introduced software for calculation of an axial static stability and management of airplanes for basic pilot training. The purpose of this software is to provide a quicker and an easier way of getting results regarding preliminary calculation of stability and management for these types of airplanes. The program is based upon analisys of data gathered from a large number of tested airplanes of this class. The accuracy of the program has been tested on the airplane type „Lasta“ and results were more than satisfying, especially regarding the fact that the program is meant to be used for preliminary calculation.

Key words: axial static stability, management, brunt, substitution for stability, neutral point.

\section{Uvod}

Pojmovi stabilnost i upravljivost interesantni su naučnicima od početka razvoja avijacije. Većina udesa koji su se dogodili na prvim avionima bili su vezani za stabilnost. Zbog toga se pristupilo pažljivom proučavanju ove problematike, koja se tiče stabilnosti i upravljivosti. Takođe, ove pojave se uzimaju kao važne granice, koje dozvoljavaju avionu njegovu namenu da se kreće u letu, sa pozitivnom ili negativnom stabilnošću.
Avion je u toku leta izložen dejstvu turbulencije i opšte uzburkanosti atmosfere, kao i udarima vetra, ali može biti izložen i trenutnim poremećajima koje izaziva pilot, voljno ili nevoljno, pomeranjem komandi krmila, trzajem vatrenog oružja i tome slično. Ako rezultujuće sile i momenti nakon uznemirenja vrate avion $\mathrm{u}$ prvobitni ravnotežni položaj, bez ikakvog angažovanja pilota, on je statički stabilan. Ukoliko novonastale sile i momenti stvore kretanje koje ga sve više udaljuje od ravnotežnog položaja, on je statički nestabi- 
lan. Ako poremećaj ne stvara nove sile i momente, tako da avion nema tendenciju da se vrati ili još više udalji od ravnotežnog položaja, on je statički neutralno stabilan.

Avion koji je statički stabilan ne mora biti i dinamički stabilan, već može biti čak i nestabilan. Međutim, statički nestabilan avion biće uvek i dinamički nestabilan. Odatle se može izvući vrlo važan zaključak da je statička stabilnost nužan, ali ne i dovoljan uslov za stabilnost.

U fazi projektovanja aviona prvi rezultati dobijaju se analitičkim metodama proračuna. $\mathrm{Na}$ osnovu toga došlo se na ideju da se uradi softver koji bi konstruktorima omogućio brzo i lako dobijanje potrebnih podataka, vezanih za stabilnost i upravljivost aviona za osnovnu obuku pilota.

\section{Analiza parametara statičke stabilnosti}

Pri projektovanju softvera izvršena je analiza postojećih konstrukcijskih rešenja iz klase aviona za osnovnu obuku pilota sa elisnom pogonskom grupom. Analiza je izvršena radi određivanja granica u kojima se nalaze parametri vezani za geometriju aviona i parametri statičke stabilnosti.

$\mathrm{Za}$ analizu je odabrano 14 aviona, od kojih su neki sa klipnom, a neki sa turboelisnom pogonskom grupom različitih snaga.

U tabelama 1 i 2 prikazane su geometrijske karakteristike krila i horizontalnog repa analiziranih aviona. Na slici 1 grafički je prikazana raspodela vitkosti, a na slici 2 raspodela odnosa rastojanja aerodinamičkog centra horizontalnog repa od težišta aviona prema srednjoj aerodinamičkoj tetivi analiziranih aviona.

Tabela 1

Geometrijske karakteristike krila analiziranih aviona

\begin{tabular}{|c|c|c|c|c|c|c|c|c|}
\hline \multirow{2}{*}{ Naziv aviona } & \multirow{2}{*}{$\begin{array}{c}\text { Tip pogonsk } \\
\text { grupe }\end{array}$} & \multicolumn{7}{|c|}{ Krilo } \\
\cline { 3 - 9 } & & $\begin{array}{c}\mathrm{S} \\
{[\mathrm{m}]^{2}}\end{array}$ & $\begin{array}{c}\mathrm{b} \\
{[\mathrm{m}]}\end{array}$ & $\begin{array}{c}1_{\mathrm{s}} \\
{[\mathrm{m}]}\end{array}$ & $\begin{array}{c}\mathrm{l}_{\mathrm{k}} \\
{[\mathrm{m}]}\end{array}$ & $\lambda$ & $\mathrm{n}$ & $\begin{array}{c}1_{\text {sat }} \\
{[\mathrm{m}]}\end{array}$ \\
\hline A10B BASIC TRAINER & turboelisna & 20.00 & 11.00 & 2.424 & 1.210 & 6.05 & 0.50 & 1.88 \\
\hline $\begin{array}{c}\text { EMBRAER EMB-321 } \\
\text { TUKANO }\end{array}$ & turboelisna & 19.40 & 11.14 & 2.300 & 1.070 & 6.40 & 0.47 & 1.76 \\
\hline ENAER T-35 PILLAN & klipna & 13.64 & 8.81 & 1.880 & 1.260 & 5.69 & 0.67 & 1.59 \\
\hline ZLIN 142 & klipna & 13.15 & 9.16 & 1.420 & 1.420 & 6.38 & 1.00 & 1.42 \\
\hline VALMET L-80 TP & turboelisna & 14.75 & 10.15 & 1.830 & 1.038 & 6.98 & 0.57 & 1.47 \\
\hline $\begin{array}{c}\text { AEROSPATIALE } \\
\text { EPSILON }\end{array}$ & klipna & 9.00 & 7.92 & 1.460 & 0.920 & 6.97 & 0.63 & 1.21 \\
\hline $\begin{array}{c}\text { SIAI-MARCHETTI } \\
\text { SF.260TP }\end{array}$ & klipna & 10.10 & 8.35 & 1.600 & 0.784 & 6.90 & 0.49 & 1.24 \\
\hline PZL-130 ORLIK & klipna & 12.30 & 8.00 & 2.000 & 1.166 & 5.20 & 0.58 & 1.62 \\
\hline YAKOVLEV Yak-52 & klipna & 15.00 & 9.30 & 1.997 & 1.082 & 5.77 & 0.54 & 1.58 \\
\hline PILATUS PC-7 & turboelisna & 16.60 & 10.40 & 1.890 & 1.080 & 6.52 & 0.57 & 1.52 \\
\hline PILATUS PC-9 & turboelisna & 16.29 & 10.12 & 1.890 & 1.080 & 6.29 & 0.57 & 1.52 \\
\hline NAC FIRECRACKER & turboelisna & 11.89 & 7.92 & 1.830 & 1.450 & 5.28 & 0.79 & 1.65 \\
\hline UTVA 75 & klipna & 14.63 & 9.73 & 1.550 & 1.550 & 6.47 & 1.00 & 1.55 \\
\hline LASTA & klipna & 11.00 & 8.34 & 1.590 & 0.870 & 6.32 & 0.55 & 1.27 \\
\hline
\end{tabular}


Geometrijske karakteristike horizontalnog repa analiziranih aviona

\begin{tabular}{|c|c|c|c|c|c|c|c|c|c|c|c|}
\hline \multirow{2}{*}{ Naziv aviona } & \multicolumn{7}{|c|}{ Horizontalni rep } \\
\cline { 2 - 14 } & $\begin{array}{c}\mathrm{S}_{\mathrm{h}} \\
{[\mathrm{m}]^{2}}\end{array}$ & $\begin{array}{c}\mathrm{b}_{\mathrm{h}} \\
{[\mathrm{m}]}\end{array}$ & $\begin{array}{c}1_{\mathrm{s}} \\
{[\mathrm{m}]}\end{array}$ & $\begin{array}{c}1_{\mathrm{k}} \\
{[\mathrm{m}]}\end{array}$ & $\lambda_{\mathrm{h}}$ & $\mathrm{n}_{\mathrm{h}}$ & $\begin{array}{c}\mathrm{d}_{\mathrm{h}} \\
{[\mathrm{m}]}\end{array}$ & $\begin{array}{c}1_{\mathrm{t}} \\
{[\mathrm{m}]}\end{array}$ & $\frac{d_{h}}{l_{\text {sat }}}$ & $\frac{S_{h}}{S}$ & $\mathrm{~V}_{\mathrm{h}}$ \\
\hline A10B BASIC TRAINER & 5.40 & 4.5 & 1.50 & 1.04 & 3.75 & 0.69 & 5.06 & 10.300 & 2.685 & 0.27 & 0.72 \\
\hline $\begin{array}{c}\text { EMBRAER EMB-321 } \\
\text { TUKANO }\end{array}$ & 6.77 & 4.660 & 1.35 & 0.73 & 3.21 & 0.54 & 4.97 & 9.860 & 2.824 & 0.35 & 0.99 \\
\hline ENAER T-35 PILLAN & 2.34 & 3.050 & 0.83 & 0.83 & 3.98 & 1.00 & 4.77 & 7.970 & 2.999 & 0.17 & 0.51 \\
\hline ZLIN 142 & 2.59 & 2.904 & 0.81 & 0.81 & 3.26 & 1.00 & 3.59 & 7.330 & 2.528 & 0.20 & 0.50 \\
\hline VALMET L-80 TP & 3.29 & 3.680 & 0.88 & 0.88 & 4.12 & 1.00 & 4.31 & 7.900 & 2.931 & 0.22 & 0.65 \\
\hline $\begin{array}{c}\text { AEROSPATIALE } \\
\text { EPSILON }\end{array}$ & 2.00 & 3.200 & 0.77 & 0.47 & 5.12 & 0.61 & 4.24 & 7.590 & 3.503 & 0.22 & 0.78 \\
\hline $\begin{array}{c}\text { SIAI-MARCHETTI } \\
\text { SF.260TP }\end{array}$ & 2.42 & 3.010 & 1.05 & 0.55 & 3.74 & 0.52 & 3.87 & 7.100 & 3.125 & 0.24 & 0.75 \\
\hline PZL-130 ORLIK & 2.78 & 3.500 & 0.84 & 0.84 & 4.41 & 1.00 & 4.81 & 8.450 & 2.970 & 0.23 & 0.67 \\
\hline YAKOVLEV Yak-52 & 2.86 & 3.160 & 1.26 & 0.72 & 3.49 & 0.57 & 4.12 & 7.745 & 2.600 & 0.19 & 0.50 \\
\hline PILATUS PC-7 & 3.18 & 3.400 & 1.37 & 0.77 & 3.64 & 0.56 & 4.89 & 9.775 & 3.213 & 0.19 & 0.62 \\
\hline PILATUS PC-9 & 3.40 & 3.400 & 1.28 & 0.77 & 3.40 & 0.60 & 5.22 & 10.175 & 3.430 & 0.21 & 0.72 \\
\hline NAC FIRECRACKER & 2.83 & 3.350 & 0.83 & 0.83 & 3.97 & 1.00 & 4.64 & 8.330 & 2.817 & 0.24 & 0.67 \\
\hline UTVA 75 & 3.34 & 3.800 & 0.91 & 0.91 & 4.32 & 1.00 & 4.14 & 7.110 & 2.671 & 0.23 & 0.61 \\
\hline LASTA & 2.00 & 3.400 & 0.84 & 0.59 & 5.78 & 0.70 & 4.17 & 8.040 & 3.296 & 0.18 & 0.60 \\
\hline
\end{tabular}

\section{Opis softvera}

Pri projektovanju ovog programa, težnja je bila da program bude pregledan i jednostavan za upotrebu. Upravo zbog toga program se sastoji od jednog prozora (slika 3) na kojem se nalaze sve potrebne kartice koje služe za unos podataka vezanih za pojedine delove aviona. Pored svih polja za unos, osim što postoji

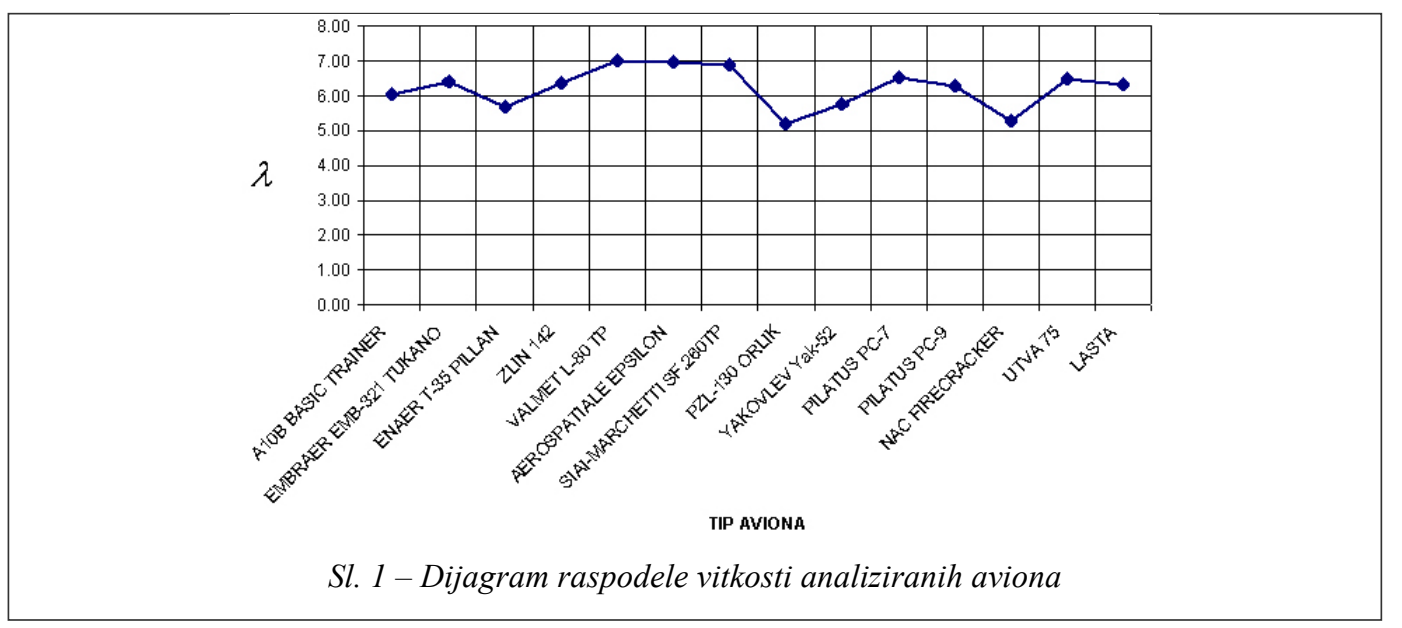




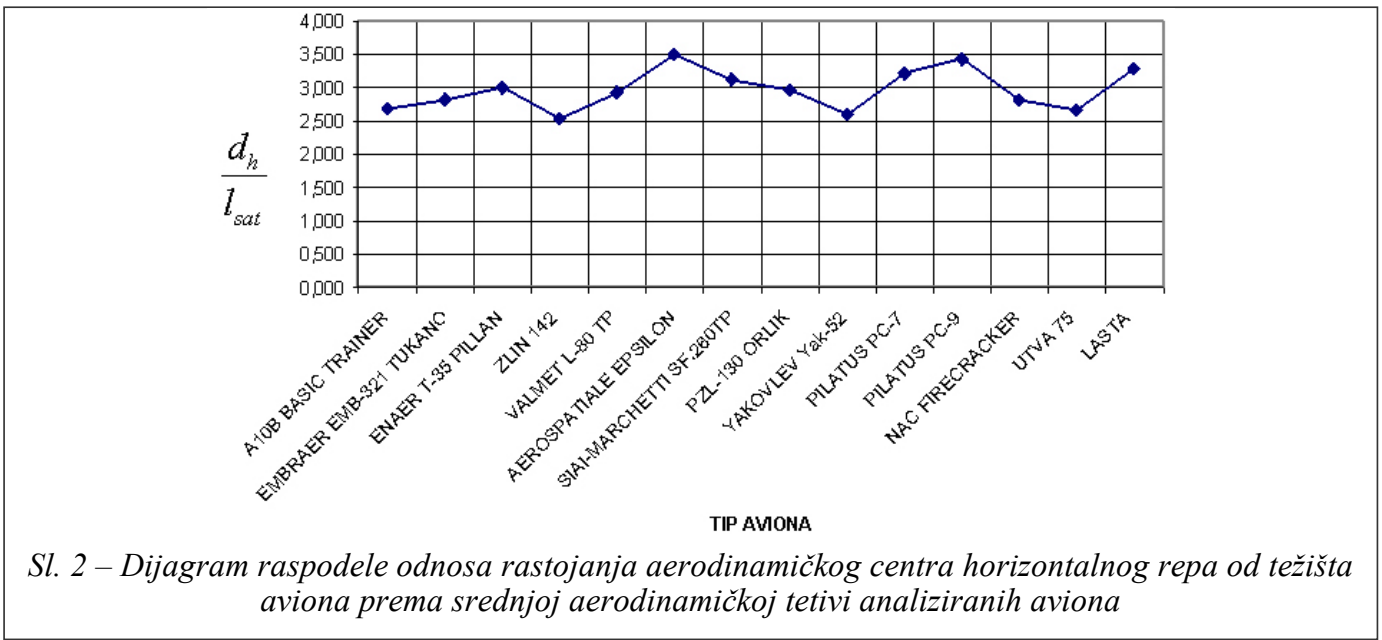

oznaka podatka, dat je i njen puni naziv, a sa desne strane polja nalazi se jedinica mere u kojoj treba uneti podatak. Sve to korisniku olakšava upotrebu i sprečava da dođe do pogreški koje mogu da nastanu pri unosu podataka.

\section{Doprinos krila uzdužnoj statičkoj stabilnosti}

Položaj težišta ima veliki uticaj na doprinos krila uzdužnoj statičkoj stabil- nosti. Položaj težišta iznad ili ispod aerodinamičkog centra (ac.) krila znatno manje utiče na stabilnost od položaja težišta ispred ili iza ac. krila. Položaj težišta iza i iznad ac. krila deluje destabilizirajuće, dok položaj težišta ispred i ispod ac. deluje stabilizirajuće.

Doprinos krila uzdužnoj statičkoj stabilnosti aviona dat je u odnosu na prikazani koordinatni sistem na slici 5, unet u kartici koja nosi naziv krilo (slika 4).

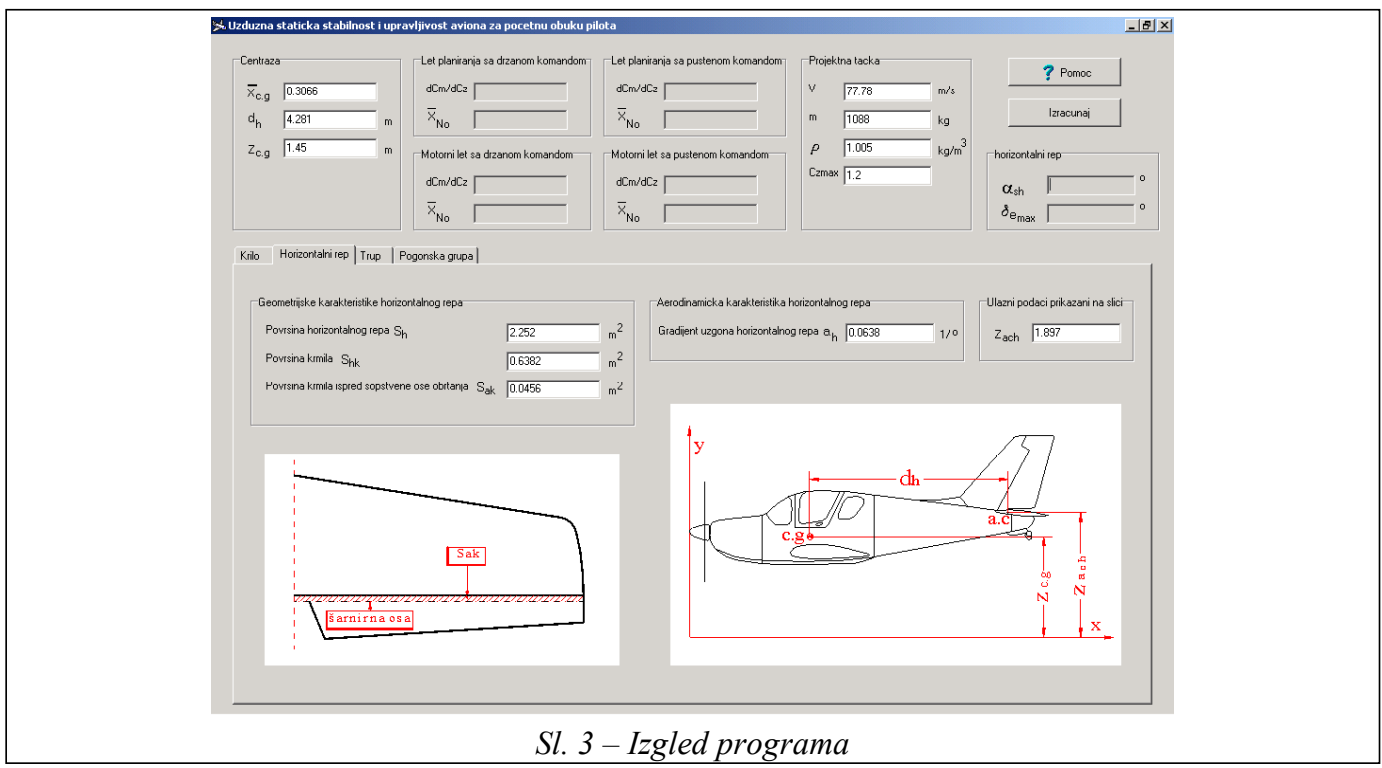




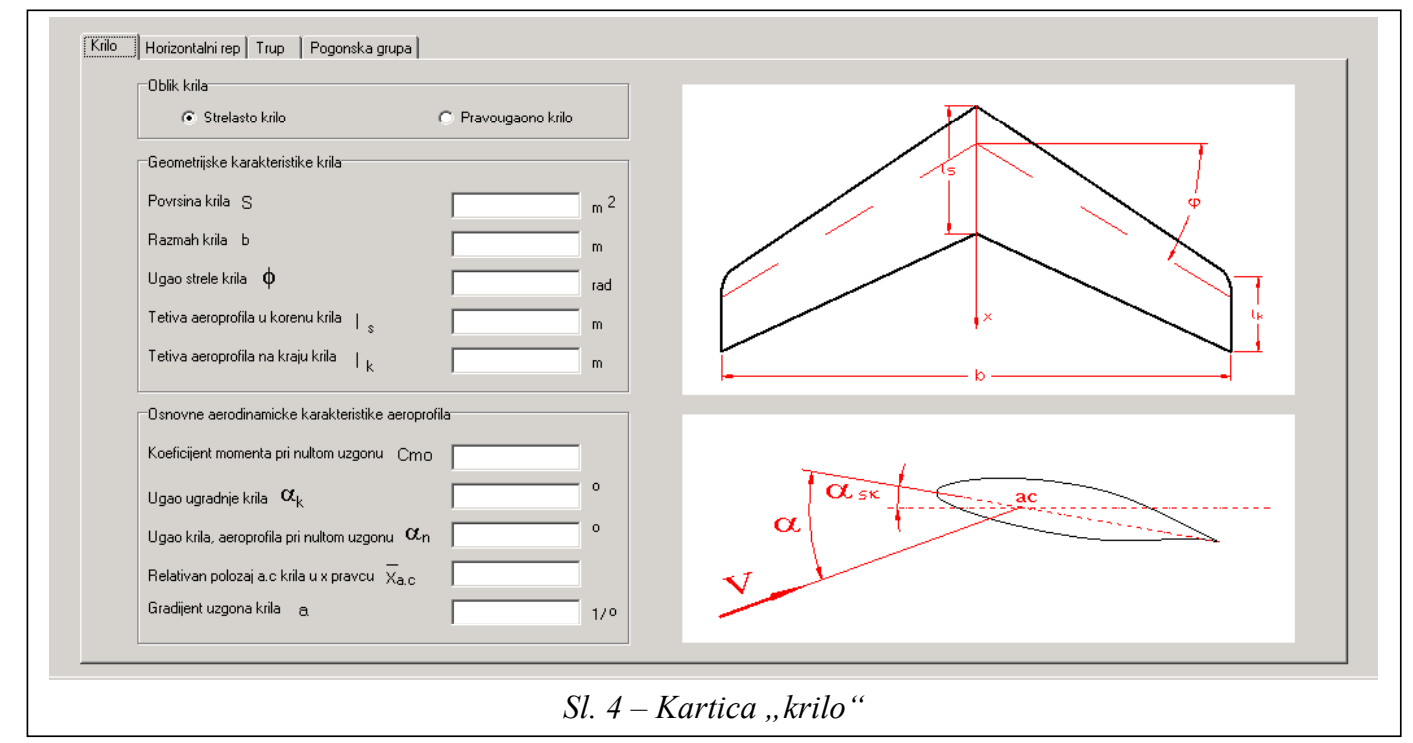

Doprinos krila stabilnosti u programu dat je sledećom jednačinom:

$$
\begin{aligned}
& \left(\frac{d C_{m k}}{d C_{z}}\right)_{k}=\frac{x_{a}}{l_{s a t}}+ \\
& +\left[\frac{2 C_{z}}{\pi \cdot \lambda \cdot e}-\left(\alpha-\alpha_{k}\right)-C_{z} \frac{1}{a}\right] \frac{z_{a}}{l_{\text {sat }}}
\end{aligned}
$$

gde je:

$\alpha$ - napadni ugao,

$\alpha_{\mathrm{k}}$ - ugao ugradnje krila,
$\mathrm{Z}_{\mathrm{a}}$ - visinsko rastojanje težišta aviona od aerodinamičkog centra krila,

$\mathrm{x}_{\mathrm{a}}$ - udaljenost težišta aviona od aerodinamičkog centra krila,

$1_{s a t}$ - srednja aerodinamička tetiva,

$\lambda$ - vitkost krila,

$\mathrm{C}_{z}$ - koeficijent uzgona,

$\mathrm{e}=1 /(1+\delta)-$ Oswaldov faktor efikasnosti razmaha,

$\delta$ - popravni koeficijent,

a - gradijent uzgona krila.

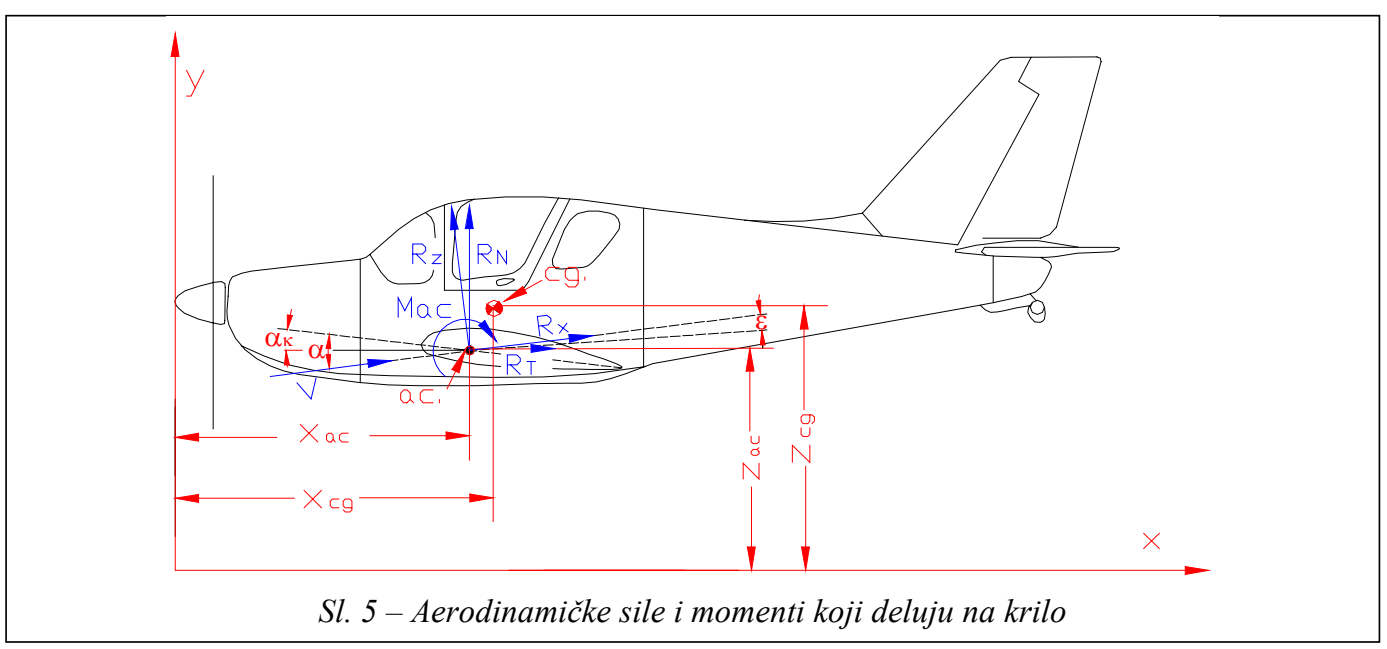




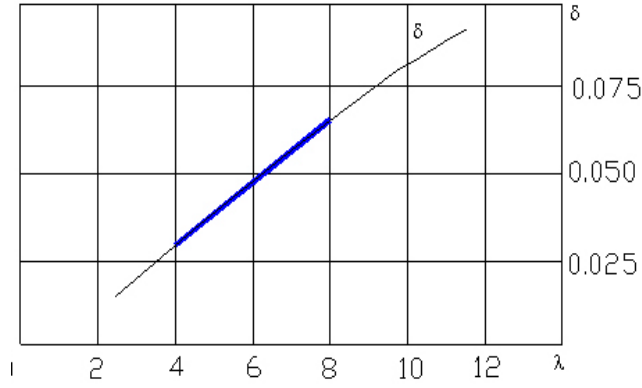

Sl. 6-Dijagram zavisnosti popravnog koeficijenta od vitkosti

$\mathrm{Na}$ primeru Oswaldovog faktora efikasnosti razmaha prikazan je princip po kojem je program automatizovan. Kao što se vidi na slici 1 , vitkost krila kod aviona za osnovnu obuku pilota kreće se u granicama od 5 do 7 , pa se sa dijagrama (slika 6) zavisnosti popravnog koeficijenta od vitkosti uzima deo krive koja se nalazi u granicama od 4 do 8 i prevodi u oblik funkcije:

$\delta=0,0089042 \lambda-0,0061$

$\mathrm{Na}$ ovom principu su svi koeficijenti potrebni za proračun prevedeni $\mathrm{u}$ obliku funkcije, a program ih, na osnovu algo- ritma koji mu je zadat, poziva i koristi $u$ proračunu.

\section{Horizontalni rep}

Doprinos horizontalnog repa uzdužnoj statičkoj stabilnosti aviona je veliki i zavisi od sledećih faktora: od udaljenosti horizontalnog repa od ac. krila, od položaja horizontalnog repa po visini, uticaja strujanja iza elise, itd.

Doprinos horizontalnog repa uzdužnoj statičkoj stabilnosti dat je sledećom jednačinom:

$$
\left(\frac{d C_{m}}{d C_{z}}\right)_{h}=-\frac{a_{h}}{a}\left(1-\frac{d \varepsilon}{d \alpha}\right) \bar{V}_{h} \eta_{h}
$$

gde je:

$a_{h}$ - gradijent uzgona horizontalnog repa,

$\bar{V}_{h}$ - volumetrijski koeficijent horizontalnog repa,

$\eta_{h}$-gradijent uzgona,

$\varepsilon$ - ugao povijanja vazdušne struje iza krila.

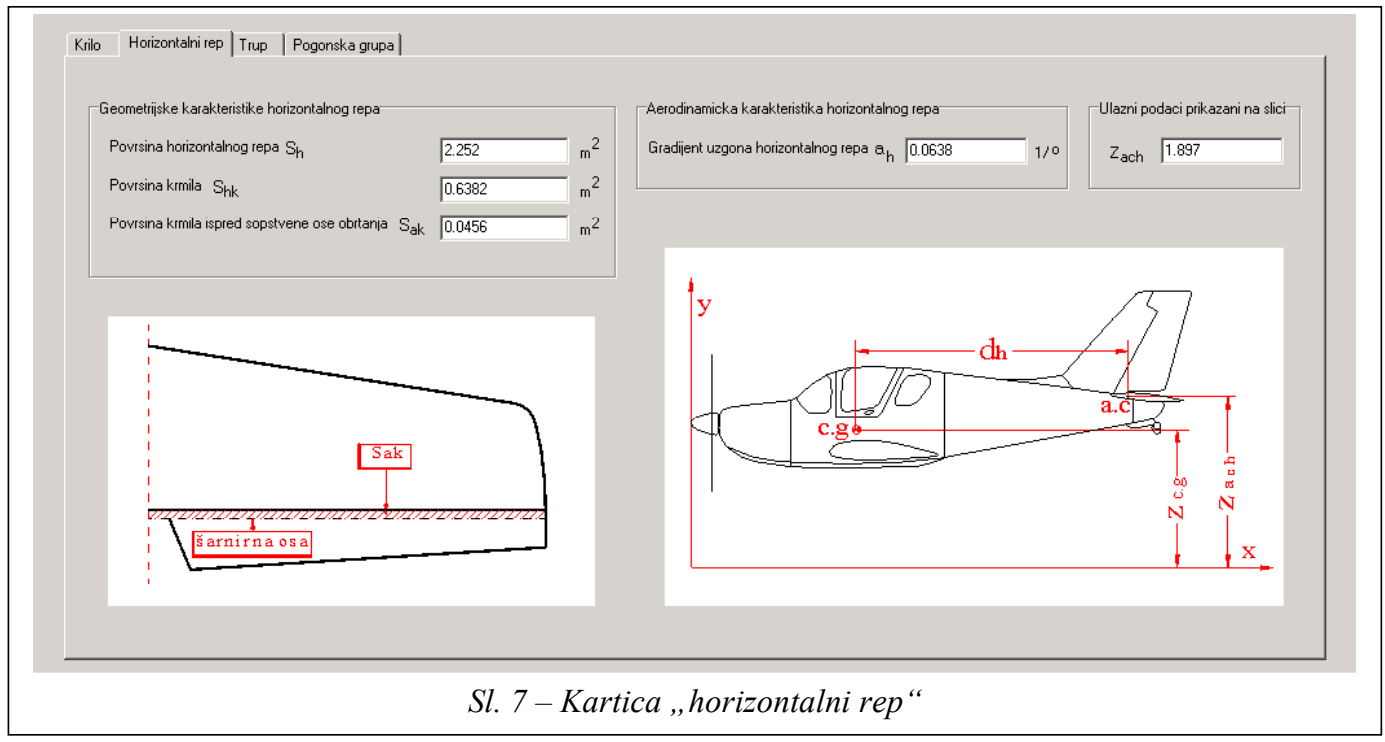


Trup

Doprinos trupa uzdužnoj stabilnosti je destabilizirajući. Ispitivanja pokazuju da povijanje struje ispred i iza krila, koje prouzrokuju indukovane brzine slobodnih vrtloga krila, imaju veliki uticaj na promenu momenta trupa i gondola sa promenom napadnog ugla.

Indukovane brzine ispred krila, koje stvaraju usponsko strujanje, utiču destabilizirajuće na sve delove trupa koji se nalaze ispred krila, dok indukovane brzine iza krila, koje uspostavljaju nisponsko strujanje, smanjuju destabilizirajući efekt onih delova trupa koji se nalaze iza krila.

Uticaj trupa na uzdužnu statičku stabilnost dat je pomoću grafo-analitičke metode:

$C_{m \alpha}=\frac{d C_{m}}{d \alpha}=\frac{\pi^{2}}{360 \cdot S \cdot l_{\text {sat }}} \int_{0}^{l} s^{2}(x)$.

$\cdot\left(\frac{d \bar{\varepsilon}}{d \alpha}\right) \cdot d x$

gde je:

$S$ - površina krila,

$s$ - širina segmenta trupa.

Veličina $d \bar{\varepsilon} / d \alpha$ za segmente trupa ispred krila, neposredno ispred krila i za segmente trupa iza krila ima različite vrednosti, a program ih sam određuje na osnovu algoritma. Potrebno je samo da korisnik vodi računa pri unosu podataka u tabele koje su date na slici 8 . U prvu tabelu treba da unese vrednosti za segmente ispred krila, u drugu samo vrednost za segment koji se nalazi neposredno uz krilo i u treću tabelu podatke za segmente koji se nalaze iza krila.

\section{Pogonska grupa}

Pogonska grupa ima veliki uticaj, kako na uzdužno uravnoteženje, tako i na uzdužnu stabilnost aviona. Pošto je teško razmatrati uticaj pogonske grupe uopšteno, a kako su odabrani avioni za osnovnu obuku pilota, razmotriće se uticaj pogonske grupe sa elisom na stabilnost i uravnoteženje.

Pogonska grupa sa elisom svoj uticaj ispoljava na sledeći način:

- uticaj vučne i normalne sile elise,

- povećanje dinamičkog pritiska na horizontalnom repu,

- povećano povijanje kod horizontalnog repa zbog uticaja mlaza elise,

- promena momenta krila zbog uticaja mlaza.

Kod elise se javljaju vučna i normalna sila. Doprinos vučne i normalne sile elise na uzdužnu statičku stabilnost dat je sledećom jednačinom:

$$
\frac{C m_{p g}}{d C_{z}}=\frac{d C_{T}}{d C_{z}} \frac{2 D^{2}}{S} \cdot \frac{z_{T}}{l_{s a t}}+\frac{d C_{N e}}{d C_{z}} \frac{\pi D^{2}}{4 S} \cdot \frac{L_{e}}{l_{s a t}}
$$

gde je:

$D$ - prečnik elise,

$L_{e}$ - rastojanje normalne sile elise od težišta aviona,

$z_{T}$ - rastojanje pravca vučne sile od težišta aviona.

Vrednost za gradijente $d C_{T} / d C_{z}$ i $d C_{N e} / d C_{z}$ treba odrediti za svaki pojedinačan slučaj i to program radi automatski.

Posredni uticaj mlaza elise na uzdužno uravnoteženje i uzdužnu stabilnost aviona ispoljava se $\mathrm{u}$ promeni karakteristika strujnog polja usled mlaza elise i promene aerodinamičkih karakteristika onih delova aviona koji se nalaze u mlazu. 


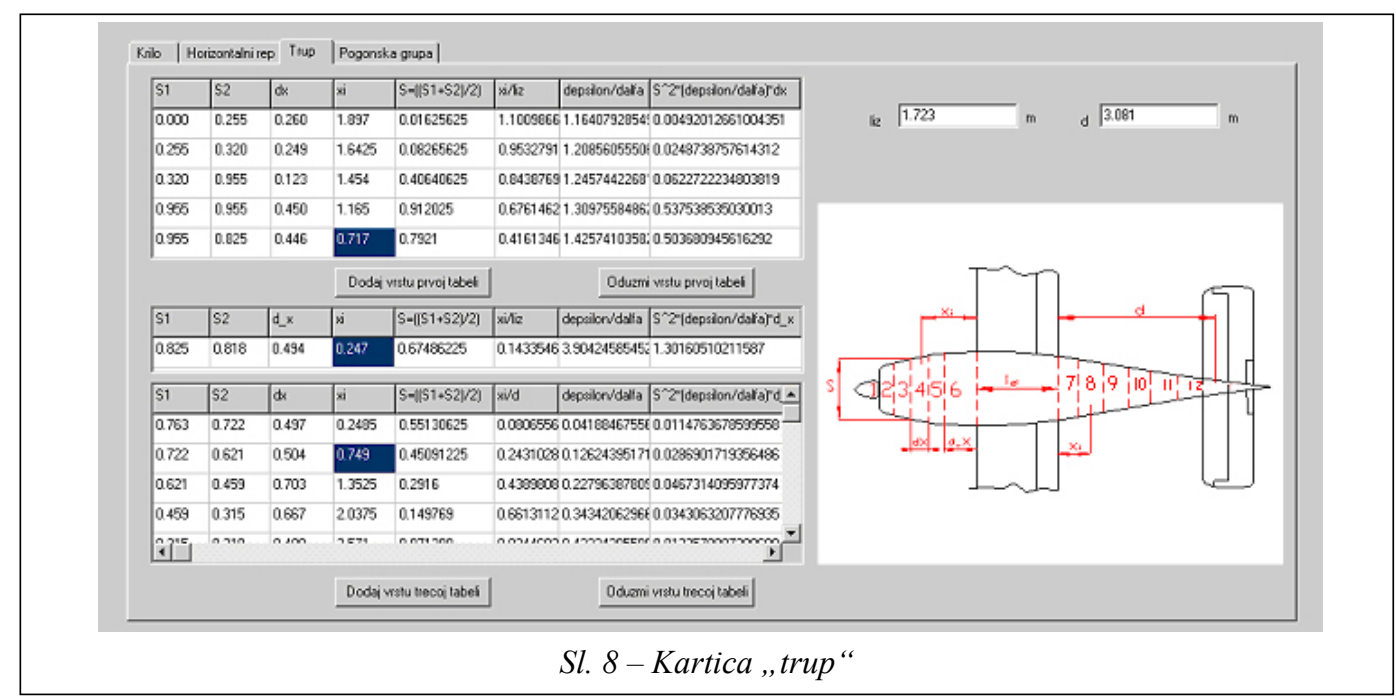

Koeficijent momenta horizontalnog repa, pod pretpostavkom da se ceo nalazi u mlazu iza elise, iznosi:

$$
\begin{aligned}
& \frac{d C_{m h}}{d C_{z}}=-\frac{a_{h}}{a} \bar{V}_{h}\left(1-\frac{d \varepsilon}{d \alpha}-\frac{d \varepsilon_{e}}{d \alpha}\right)^{2} \\
& \left(1+\frac{8 C_{T}}{\pi}\right)^{2}-C_{n h} \bar{V}_{h} \frac{d\left(1+\frac{8 C_{T}}{\pi}\right)^{2}}{d C_{z}}
\end{aligned}
$$

gde je: $\varepsilon_{e}$ - ugao povijanja od elise,

$V_{m}$ - brzina u mlazu,

$C_{T}$ - koeficijent propulzivne sile.

Veličina ugla $\varepsilon_{e}$ povijanja struje iza elise zavisi od koeficijenta propulzivne sile $C_{T}$.

\section{Pregled rezultata}

Glavni prozor programa prikazan je na slici 3. U gornjoj polovini prozora na-

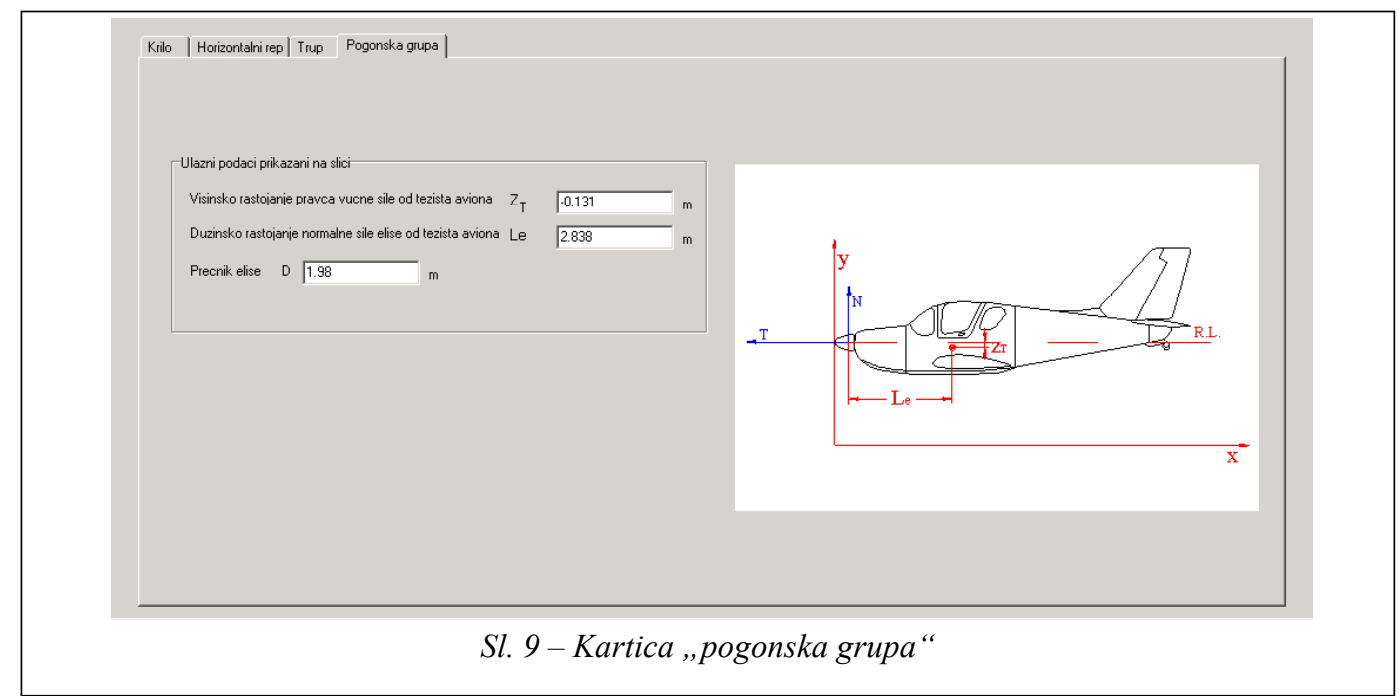




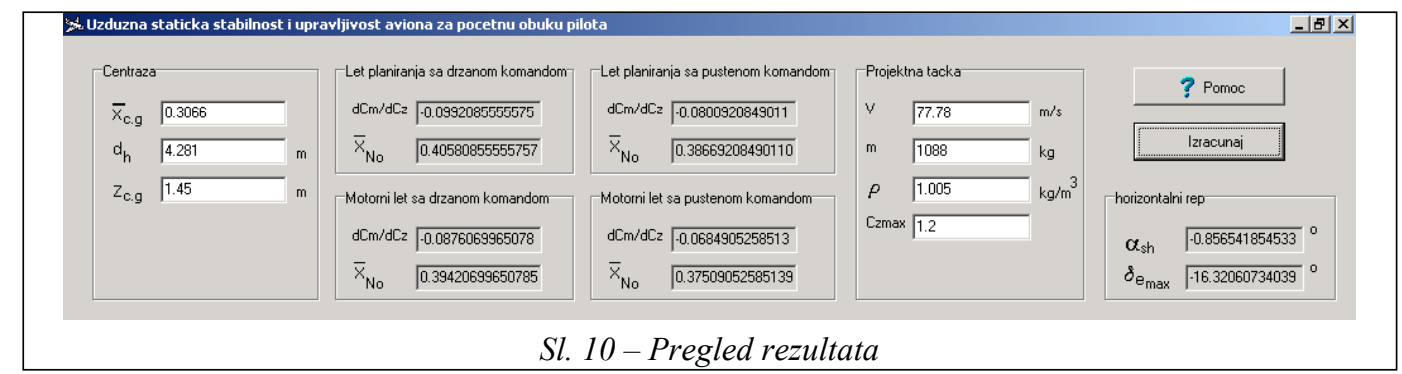

laze se polja sa imenima grupe podataka koji treba da se unesu ili koji će se dobiti kao rezultat (slika 10). Tako postoje grupe podataka sa imenima ,,centraža“, ,,let planiranja sa držanom komandom“, „,motorni let sa držanom komandom“, „let planiranja sa puštenom komandom“, „motorni let sa puštenom komandom“, „projektna tačka“"i ,horizontalni rep“.

Grupa podataka „centraža“ služi za unos podataka za centražu (prednju, zadnju i uobičajenu centražu). Vrši se unos sledećih podataka:

$\overline{\mathrm{X}}_{\text {c.g }}-$ relativan položaj težišta $\mathrm{u} x$ pravcu,

$\mathrm{d}_{\mathrm{h}}$ - dužina od težišta aviona do $1 / 4$ tetive horizontalnog repa,

$\mathrm{z}_{\mathrm{c.g}}$ - visinsko rastojanje težišta aviona od x-ose.

U grupama podataka „let planiranja sa držanom komandom“, „motorni let sa držanom komandom“, „let planiranja sa puštenom komandom“ i „motorni let sa puštenom komandom" prikazuju se rezultati rada programa: $\mathrm{dCm} / \mathrm{dCz}-$ rezerva stabilnosti i $\overline{\mathrm{x}}_{\mathrm{No}}-$ relativan položaj neutralne tačke.

Grupa podataka „projektna tačka“ služi za unos podataka za projektnu tačku za koju se vrši proračun ugla ugradnje horizontalnog repa i maksimalni otklon krmila koji je potreban za tu projektnu tačku. Unose se sledeći podaci:
V - brzina horizontalnog leta,

$\mathrm{m}$ - masa aviona u projektnoj tački,

$\rho$ - gustina vazduha na visini horizontalnog leta,

$\mathrm{C}_{\mathrm{zmax}}$ - maksimalni koeficijent uzgona.

U grupi „horizontalni rep“ prikazuju se rezultati rada programa: $\alpha_{\text {sh }}$ - ugao ugradnje horizontalnog repa i $\delta_{\text {emax }}-$ maksimalni otklon krmila visine.

U gornjem desnom uglu nalazi se opcija „Pomoć“. Klikom na tu funkciju otvara se prozor u kojem se nalazi objašnjenje programa. Ispod njega nalazi se dugme „Izračunaj“, a pritiskom na njega izvršava se program. Ako nisu uneti svi podaci otvoriće se prozor sa upozorenjem: „Niste uneli sve potrebne podatke, unesite ih!!!“. Posle klika na „OK“ unose se podaci koji nisu uneti (slika 11).

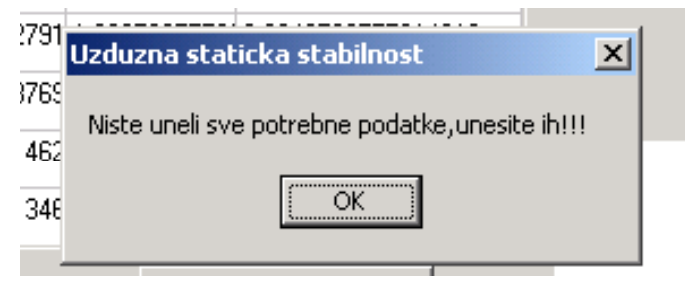

Sl. 11 - Upozorenje

\section{Zaključak}

Proračun stabilnosti i upravljivosti aviona pri projektovanju vrlo je bitan. Softver koji je prikazan u ovom radu obezbe- 
đuje da konstruktor lako i brzo dođe do podataka vezanih za uzdužnu statičku stabilnost i upravljivost aviona. Najveća prednost ovog programa je automatizacija. Do sada je konstruktor pri projektovanju morao da koristi parametre sa više dijagrama koji nisu bili na jednom mestu (u više različitih izvora). Sada je taj problem prevaziđen korišćenjem ovog programa. Pošto je program testiran i dao je zadovoljavajuće rezultate, sledeći korak je da se unapredi i za ostale tipove aviona, kao i za poprečnu statičku stabilnost i upravljivost, uzdužnu i poprečnu dinamičku stabilnost.

Literatura:

[1] Rendulić, Z.: Mehanika leta, Vojnoizdavački i novinski centar, Beograd, 1987.

[2] Nenadović, M.: Stabilnost i upravljivost letelica, Prvi deo, Mašinski fakultet, Beograd, 1971.

[3] Clancy, L. J.: Aerodynamics, Pitmann Publishing, 1975.

[4] Seckel, E.: Stability and Control of Airplanes and Helicopters, Academic Press, New York, 1964.

[5] Miele, A.: Steady Properly Banked Turns of Turbojet-Propelled Airplanes, NACA TM No 1382, 1955.

[6] MIL F-8785 C (vazduhoplovni propisi). 